\title{
Prediction of concurrent keypeck treadle-press responding from simple schedule performance
}

\author{
FRANCES K. MCSWEENEY \\ Washington State University, Pullman, Washington 99164
}

\begin{abstract}
Four pigeons pecked keys and pressed treadles for food reinforcers delivered by several variable-interval schedules of reinforcement. Then the subjects responded on several concurrent schedules. Keypecking produced reinforcers in one component, and treadle-pressing produced reinforcers in the other. The changeover delay, which prevented reinforcement after all switches from one response to the other, was 0,5 , or 20 sec long. An equation proposed by Fierrnstein (1970) described the rates of treadle-pressing and keypecking emitted during the variableinterval schedules. The $\mathbf{k}$ parameter of this equation was larger for keypecking than for treadle-pressing. The $R_{0}$ parameters were not systematically different for the two responses. The rates of keypecking and treadle-pressing emitted during the components of the concurrent schedules correlated with, but were not equal to, the rates of responding predicted by Herrnstein's equation and the subject's simple schedule responding. The ratios of the rates of responding emitted during, and the ratios of the time spent responding on, the components of the concurrent schedules conformed to an equation proposed by Baum (1974), but not to Herrnstein's equation.
\end{abstract}

Herrnstein (1970) proposed that Equation 1 described the behavior of animals responding on simple and complex schedules of reinforcement:

$$
P_{1}=\frac{k R_{1}}{R_{1}+m R_{2}+R_{0}}
$$

$P_{1}$ is the rate of responding generated by a rate of reinforcement equal to $R_{1} . P_{2}$ is the rate of responding generated by a second rate of reinforcement, $R_{2}$, if one is available. The constants $k, m$, and $R_{0}$ are parameters which are estimated from the data with certain restrictions; $\mathrm{m}$ equals 1.0 for concurrent schedules, but $0 \leqslant \mathrm{~m} \leqslant 1.0$ for multiple schedules (Herrnstein, 1970); $k$ is the subject's asymptotic rate of responding, measured in responses per time unit. Its size varies only with the subject and with the form of the response. It does not change with changes in reinforcement (Herrnstein, 1974). $R_{0}$ is the rate of reinforcement which the subject obtains without responding. It is measured in reinforcers per time unit (Herrnstein, 1974). Its value may change as a function of several variables, such as the degree of the subject's deprivation for the programmed reinforcer (Herrnstein \& Loveland, 1974).

Equation 1 has received extensive support (e.g., DeVilliers, 1977), but several of its predictions have

The author wishes to thank G. Grammer, K. Kearney, and D. Smolar for their assistance in running the subjects. Reprints may be obtained from F. K. McSweeney, Department of Psychology, Washington State University, Pullman, Washington 99164. This research was supported by NIMH Grant MH 28192-01 to the author. not been tested. First, Equation 1 has described the responding of pigeons pecking keys (e.g., Herrnstein, 1970) and of rats pressing bars (e.g., Baum, 1976). But it may not describe other types of responding emitted in free-operant situations. Second, Herrnstein's interpretation of the parameters of Equation 1 predicts that the size of $k$, but not the size of $R_{0}$, will change with changes in the topographical form of the response which produces reinforcement (Herrnstein, 1974). Because $\mathrm{k}$ is measured in response units, its size must change with changes in the size of these units. Herrnstein has not specified the factors which determine the size of $R_{0}$, but his interpretation of $\mathbf{R}_{\mathbf{0}}$ as reinforcers obtained from unprogrammed sources suggests that variables which influence reinforcement will change its size more than factors which influence responding. Third, Equation 1 predicts that the behavior emitted on complex schedules of reinforcement will differ from the behavior emitted on simple schedules only by the addition of a second rate of reinforcement to the denominator of the equation. $\mathbf{R}_{2}$ equals 0 for simple schedules: only one response produces reinforcement. $R_{2}$ is usually a positive number for complex schedules: two or more responses produce reinforcers. Therefore, a knowledge of the subject's simple schedule performance should help to predict its performance on a complex schedule.

The present study tested these predictions. First, pigeons pecked a key for food reinforcers delivered by several variable-interval (VI) schedules. The sizes of the $k$ and $R_{0}$ parameters for keypecking were estimated for each subject. Then the same pigeons pressed a treadle for food reinforcers delivered by several VI schedules. The sizes of the $k$ and $R_{0}$ 
parameters for treadle-pressing were estimated. Finally, the subjects responded on a concurrent keypeck treadle-press schedule. That is, pecking a key located on one side of the experimental enclosure produced reinforcers according to one schedule of reinforcement; pressing a treadle located on the other side of the experimental enclosure produced reinforcers according to another schedule. Each subject's concurrent schedule performance was predicted using Equation 1, its $\mathrm{k}$ and $\mathbf{R}_{\mathbf{0}}$ parameters for keypecking and treadle-pressing, and the rates of reinforcement obtained for emitting each response during the concurrent schedules.

\section{METHOD}

\section{Subjects}

Four naive pigeons, maintained at $80 \%$ to $85 \%$ of their freefeeding body weights, served as subjects. Subjects 6311, 3322, and 1887 were White Carneaux pigeons. Subject 404 was a homing pigeon.

\begin{abstract}
Apparatus
The apparatus was a standard three-key Grason-Stadler pigeon station, Model E6446 C, enclosed in a Grason-Stadler, Model E3125A-300, sound-attenuating chamber. Two floor treadles were added to the enclosure. Each treadle, a $5.2-\mathrm{cm}$-diam aluminum disk, was held in a resting position $2.6 \mathrm{~cm}$ above the enclosure floor by a strip of aluminum which connected it to the wall containing the magazine. The aluminum strips were $7.7 \mathrm{~cm}$ long by $1 \mathrm{~cm}$ wide. They entered the wall containing the magazine $16.8 \mathrm{~cm}$ below each of the two outer response keys. The treadles produced a brief feedback click when operated by a force greater than approximately $.25 \mathrm{~N}$ applied to their centers. Electromechanical equipment located in another room scheduled the experimental events.
\end{abstract}

\section{Procedure}

Pecking the response key, located to the subject's left as it faced the wall containing the food magazine, was shaped by a successive approximations procedure for each subject. Then keypecking was reinforced by a series of variable-interval (VI) schedules. The left key was illuminated with red light. Pecks on this key produced a brief feedback click and reinforcers when they were scheduled. The other keys were not illuminated. Pecks on the other keys and presses on the two floor treadles had no effect.

Next, pressing the treadle, locater to the subject's right when it faced the wall containing the food magazine, was shaped by a successive approximations procedure for each subject. Then treadle-pressing was reinforced by a series of variable-interval schedules. Reinforcers were scheduled by the same VI schedules which had been used when the subjects pecked keys for food reinforcers. The response key located directly above the right treadle was illuminated with white light. Pecks on this response key had no effect. Pecks on the other response keys and presses on the left treadle were also ineffective.

Third, each subject responded on a series of concurrent keypeck treadle-press schedules (conc). The key located to the subject's left as it faced the wall containing the magazine was again illuminated with red light. Pecks on this key produced a brief feedback click and reinforcers according to a VI schedule. The response key located directly above the right treadle was illuminated with white light. Presses on the treadle located below this key produced reinforcers according to a second VI schedule. Observations of the subjects from time to time during the experiment showed that they continued to press the treadle with their feet. Pecks on the right and middle response keys and presses on the left treadle had no effect. The VI schedules were selected so that keypecking produced the higher rate of reinforcement during some concurrent schedules and treadle-pressing produced the higher rate of reinforcement during other schedules.

A changeover delay (COD) penalized switches between manipulanda during some of the concurrent schedules. The COD was a period of time during which no responses were reinforced. It was initiated by all switches from one manipulandum to the other. Three different COD durations were used in this experiment. The COD was $0 \mathrm{sec}$ long for some schedules, $5 \mathrm{sec}$ long for other schedules, and $20 \mathrm{sec}$ long for a third group of schedules. Different durations were studied because the duration of the COD may determine how well the rate of responding conforms to the predictions of Herrnstein's equation when pigeons peck keys on concurrent schedules. Several studies have shown that the COD must exceed a minimal duration before Herrnstein's equations are confirmed (e.g., DeVilliers, 1977; Shull \& Pliskoff, 1967). Different values of the COD were used in the present experiment to determine if the same results would be found for concurrent keypeck treadle-press responding.

The particular keypeck, treadle-press, and concurrent schedules which were presented in this experiment appear in Table 1 in order of presentation. The numbers which appear in parentheses following the names of the schedules represent the number of reinforcers presented per session for that schedule. Each experimental session terminated when a particular number of reinforcers had been delivered. The number varied from schedule to schedule to prevent the sessions from becoming very long. Table 1 also presents the number of sessions for which each schedule was presented. Each schedule was presented until responding stabilized. Responding was considered to be stable when the rates of responding emitted on each manipulandum during the last five sessions fell within the range of rates of responding emitted on that manipulandum during the earlier sessions.

All reinforcers were scheduled according to a 20-interval series constructed by a procedure outlined by Catania and Reynolds (1968, Appendix II). They consisted of 5-sec access to the magazine containing mixed grain. A houselight, located in the upper right corner of the wall which contained the magazine, illuminated the experimental enclosure throughout all sessions. Sessions were conducted daily, five or six times per week.

\section{RESULTS}

Figure 1 presents the rates of keypecking (closed circles) and of treadle-pressing (open circles) emitted on the variable-interval schedules plotted as a function of the rates of reinforcement which the schedules provided. The rates of responding are reported in responses per minute; the rates of reinforcement, in reinforcers per hour. Rates were calculated by dividing the number of responses emitted, or the number of reinforcers obtained, during a session by the total session time minus the time for which the magazine was presented. Each point in Figure 1 represents the mean of the rates calculated for the last five sessions for which each schedule was available. The best-fitting $k$ and $R_{0}$ parameters for keypecking and treadle-pressing were calculated by a linear least-squares technique suggested by Cohen (1973) and by a nonlinear least-squares technique (Lawson \& Hanson, 1974). The techniques produced 
Table 1

Number of Sessions Spent Responding on Each Schedule and Numbers of Reinforcers Presented Per Session in Order of Presentation

\begin{tabular}{|c|c|c|c|c|c|}
\hline \multirow{2}{*}{ Schedule } & & \multicolumn{4}{|c|}{ Subject } \\
\hline & & 6311 & 3322 & 1887 & 404 \\
\hline & & \multicolumn{4}{|c|}{ Keypeck } \\
\hline VI $15-\mathrm{sec}$ & $(40)$ & 29 & 37 & 28 & 28 \\
\hline VI $1-\min$ & (40) & 26 & 18 & 27 & 27 \\
\hline VI 3-min & (15) & 16 & 16 & 16 & 16 \\
\hline VI 8-min & $(5)$ & 16 & 16 & 16 & 16 \\
\hline \multirow[t]{2}{*}{ VI $15-\mathrm{min}$} & (3) & 16 & 16 & 16 & 16 \\
\hline & & \multicolumn{4}{|c|}{ Treadle-Press } \\
\hline VI 15-sec & $(40)$ & 19 & 19 & 19 & 19 \\
\hline VI $1-1$ & & 24 & 23 & 28 & 23 \\
\hline VI 3-m & (15) & 24 & 24 & 47 & 24 \\
\hline VI 8-1 & (5) & 22 & 22 & 22 & 20 \\
\hline VI $15-\min$ & (3) & 18 & 17 & 14 & 16 \\
\hline \multirow{7}{*}{$\begin{array}{l}\text { VI 15-sec (key) } \\
\text { VI 1-min (treadle) } \\
\text { VI 1-min (treadle) } \\
\text { VI 4-min (key) } \\
\text { VI 1-min (key) } \\
\text { VI 8-min (treadle) }\end{array}$} & & \multicolumn{4}{|c|}{$\begin{array}{l}\text { Concurrent Keypeck, } \\
\text { Treadle-Press (0-Sec COD) }\end{array}$} \\
\hline & & & & & \\
\hline & $(40)$ & 36 & 37 & 39 & 37 \\
\hline & & & & & \\
\hline & (40) & 38 & 37 & 35 & 35 \\
\hline & $(40)$ & 28 & 28 & 28 & 28 \\
\hline & & \multicolumn{4}{|c|}{$\begin{array}{l}\text { Concurrent Keypeck, } \\
\text { Treadle-Press (5-Sec COD) }\end{array}$} \\
\hline VI 1-min (treadle) & & & & & \\
\hline VI 8-min (key) & $(40)$ & 31 & 31 & 46 & 46 \\
\hline $\begin{array}{l}\text { VI 1-min (key) } \\
\text { VI 4-min (treadle) }\end{array}$ & & & & & \\
\hline $\begin{array}{l}\text { VI 4-min (treadle) } \\
\text { VI 1-min (key) }\end{array}$ & $(40)$ & 27 & 27 & 23 & 30 \\
\hline \multirow{3}{*}{$\begin{array}{l}\text { VI 1-min (key) } \\
\text { VI 15-sec (treadle) }\end{array}$} & & & 48 & 31 & 25 \\
\hline & $(40)$ & \multirow{2}{*}{\multicolumn{4}{|c|}{$\begin{array}{l}\text { Concurrent Key peck, } \\
\text { Treadle-Press (20-Sec COD) }\end{array}$}} \\
\hline & & & & & \\
\hline $\begin{array}{l}\text { VI 1-min (key) } \\
\text { VI 4-min (treadle) }\end{array}$ & & & & & \\
\hline $\begin{array}{l}\text { VI 4-min (treadle) } \\
\text { VI 1-min (key) }\end{array}$ & (40) & 21 & 20 & 21 & 20 \\
\hline VI $15 \mathrm{sec}$ (treadle) & (40) & 54 & 55 & 53 & 54 \\
\hline VI 1-min (key) & & & & & \\
\hline VI 4-min (treadle) & (40) & 26 & 26 & 26 & 44 \\
\hline $\begin{array}{l}\text { VI } 1-\min (\operatorname{tre} \\
\text { VI } 2-\min (\end{array}$ & $(40)$ & 53 & 50 & 47 & 30 \\
\hline & & & & & \\
\hline
\end{tabular}

similar results. The results of the more familiar Cohen technique have been presented. They appear on the figure for each subject and for the mean of all subjects. The $\mathrm{k}$ parameters have been reported in responses per minute; the $R_{0}$ parameters, in reinforcers per hour. The parameters for keypecking appear above those for treadle-pressing in the figure.

Equation 1 accounted for $96 \%, 84 \%, 71 \%, 38 \%$, and $85 \%$ of the variance in keypecking for the four subjects and the mean of all subjects, respectively. It accounted for $89 \%, 95 \%, 76 \%, 85 \%$, and $91 \%$ of the variance in treadle-pressing for the four subjects and the mean of all subjects, respectively. The $\mathrm{k}$ parameter for keypecking was larger than the $\mathrm{k}$ parameter for treadle-pressing for each subject and for the mean of all subjects. The $R_{0}$ parameters were not systematically different. The $R_{0}$ parameter for keypecking was larger than the $\mathbf{R}_{\mathbf{0}}$ parameter for treadle-pressing for two subjects, but smaller for the other two subjects.

Figure 2 presents the rates of responding (responses per minute) emitted during the components of the concurrent schedules plotted as a function of the rates of responding predicted for these components. The predicted rates of keypecking $\left(\mathbf{P}_{\mathbf{k}}\right)$ and of treadlepressing $\left(\mathrm{P}_{t}\right)$ were calculated for each subject responding on each concurrent schedule by substituting into Equations 2 and 3, respectively:

$$
\begin{gathered}
P_{k}=\frac{k_{k} R_{k}}{R_{k}+R_{t}+R_{0 k}}, \\
P_{t}=\frac{k_{t} R_{t}}{R_{t}+R_{k}+R_{0 t}} .
\end{gathered}
$$

$K_{k}$ and $k_{t}$ are the $k$ parameters estimated for the subject for keypecking and treadle-pressing, re-

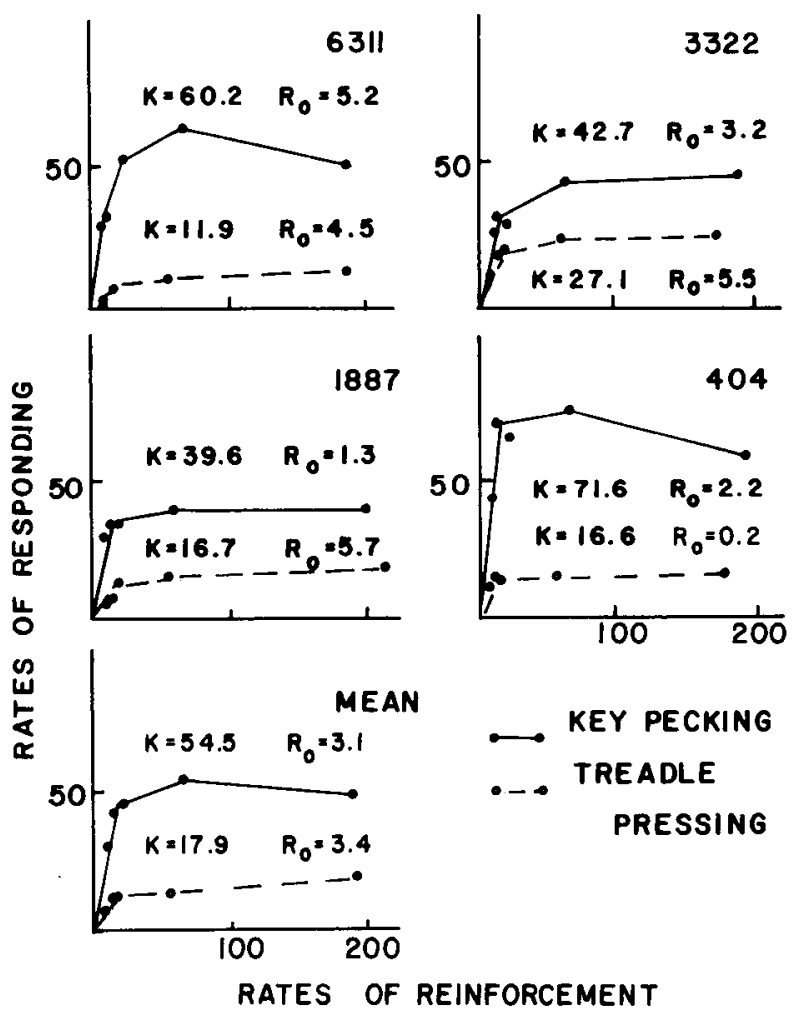

Figure 1. Mean rates of keypecking (closed circles) and of treadle-pressing (open circles) emitted during the variable-interval schedules plotted as a function of the rates of reinforcement that the schedules provided. Rates of responding are reported in responses per minute; rates of reinforcement, in reinforcers per hour. The fifth set of axes represents the mean of all subjects. The other four sets of axes represent individual subjects. The best-fitting $k$ and $R_{0}$ parameters for each response for each subject and for the mean of all subjects appear on the figure. $K$ has been reported in responses per minute; $R_{0}$, in reinforcers per hour. The parameters for keypecking appear above those for treadlepressing. 


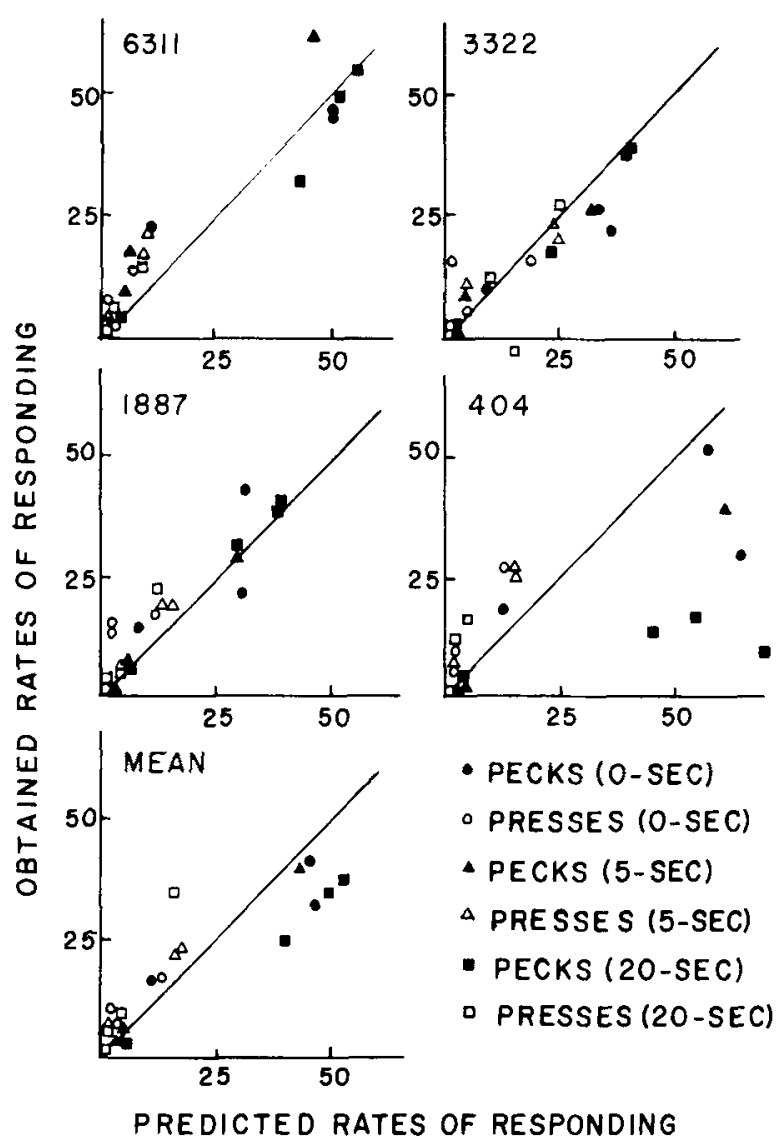

Figure 2. Mean obtained rates of responding (responses per minute) plotted as a function of the mean rates of responding (responses per minute) predicted for each subject and each concurrent schedule from Equation 1, the subject's simple schedule responding, and the rates of reinforcement obtained from the component schedules. All points are based on the mean of the statistics generated over the last five sessions for which each schedule was presented. The fifth set of axes represents the mean of all subjects; the other four sets of axes represent individual subjects. The closed points represent the rates of keypecking; the open points, the rates of treadle-pressing. All points would fall on the diagonal lines if the obtained rates of responding equaled the predicted rates.

spectively. $R_{0 k}$ and $R_{0 t}$ are the $R_{0}$ parameters for these responses. $R_{k}$ and $R_{t}$ are the rates of reinforcement which were obtained by keypecking and treadlepressing during the components of the concurrent schedule under consideration.

The obtained rates of responding, and the rates of reinforcement which were used to estimate the pre- dicted rates of responding, were calculated by dividing the number of responses emitted during, or the number of reinforcers obtained from, each component of each concurrent schedule by the total session time. The time for which the magazine was presented was excluded from the total session time. All rates wore the means of the statistics generated over the last five sessions for which each schedule was available. Rates of responding were calculated in responses per minute; rates of reinforcement, in reinforcers per hour.

A least-squares procedure was used to calculate the straight lines which best fit the points plotted on each set of axes in Figure 2. Table 2 presents the equations of these lines. The equations have been reported for all data, and for the responding emitted when the three different values of the COD were in effect. The percentage of the variance in the data which was accounted for by each equation appears in parentheses following it. The equations have not been reported separately for keypecking and treadlepressing because no systematic differences were found between the equations for the two different types of responses.

Table 2 leads to several conclusions. First, the obtained and predicted rates of responding were correlated. The equations reported in Table 2 accounted for $59 \%$ to $98 \%$ of the variance in the data for all subjects and all COD durations, except Subject 404, the 20-sec COD condition. Second, the obtained and predicted rates of responding were not exactly equal. The equations reported in Table 2 would be $y=$ $1.0 \mathrm{x}+0$ if the obtained rates of responding exactly equaled the predicted rates. But 17 of the 20 equations have slopes less than 1.0, and all of the equations have $y$-intercepts greater than 0 . Third, the obtained rates of responding generally fell closer to the predicted rates when the COD was 5 or $20 \mathrm{sec}$ long than when it was $0 \mathrm{sec}$ long. The slopes of the lines were closer to 1.0 for three of the four subjects when the COD was 5 or $20 \mathrm{sec}$ long than when it was $0 \mathrm{sec}$ long. The y-intercepts of the lines were closer to 0 for at least three of four subjects when the two longer CODs were programmed. And the equations presented in Table 2 accounted for a larger percentage of the variance in the data for three of the four subjects when the COD was 5 or $20 \mathrm{sec}$ long than when it was 0 sec long.

Table 2

Obtained Rates of Responding as a Function of Predicted Rates of Responding

\begin{tabular}{|c|c|c|c|c|c|c|c|c|c|c|c|}
\hline \multirow[b]{2}{*}{ Subject } & & & & \multicolumn{7}{|c|}{ Data From Schedules With } & \\
\hline & \multicolumn{3}{|c|}{ All Data } & \multicolumn{3}{|c|}{ 0-Sec COD } & \multicolumn{3}{|c|}{ 5-Sec COD } & \multicolumn{2}{|l|}{$20-\operatorname{Sec} \mathrm{COD}$} \\
\hline $\begin{array}{r}6311 \\
3322 \\
1887 \\
404 \\
\text { Mean }\end{array}$ & $\begin{array}{l}y= \\
y= \\
y= \\
y= \\
y=\end{array}$ & $\begin{array}{l}.87 x+5.61 \\
.75 x+3.37 \\
.94 x+4.11 \\
.30 x+12.82 \\
.65 x+6.88\end{array}$ & $\begin{array}{l}(.90) \\
(.87) \\
(.86) \\
(.16) \\
(.81)\end{array}$ & $\begin{array}{l}y= \\
y= \\
y= \\
y= \\
y=\end{array}$ & $\begin{array}{l}.75 x+7.43 \\
.43 x+8.29 \\
.70 x+9.64 \\
.53 x+10.60 \\
.61 x+8.68\end{array}$ & $\begin{array}{l}(.95) \\
(.70) \\
(.59) \\
(.77) \\
(.91)\end{array}$ & $\begin{array}{l}y=1.25 x+ \\
y=.74 x+ \\
y=1.02 x+ \\
y=.59 x+ \\
y=.87 x+\end{array}$ & $\begin{array}{l}5.43 \\
3.58 \\
2.36 \\
7.05 \\
4.71\end{array}$ & $\begin{array}{l}(.98) \\
(.94) \\
(.97) \\
(.72) \\
(.96)\end{array}$ & $\begin{array}{l}y=.88 x+2.14 \\
y=.93 x+.85 \\
y=1.02 x+2.01 \\
y=-.04 x+18.86 \\
y=.60 x+6.26\end{array}$ & $\begin{array}{l}(.96) \\
(.97) \\
(.96) \\
(.00) \\
(.74)\end{array}$ \\
\hline
\end{tabular}


The ratios of the rates of responding which would be emitted during the components of the concurrent schedule may be predicted by dividing Equation 2 by Equation 3. This may be approximately restated as Equation 4 because the $R_{0}$ parameters were not systematically different for keypecking and treadlepressing. Equation 4 has been stated for the ratio of the time spent responding on the keypeck and treadlepress components $\left(T_{k} / T_{t}\right)$ as well as for the ratios of the rates of responding emitted during the components $\left(\mathrm{P}_{k} / \mathrm{P}_{t}\right)$. Baum and Rachlin (1969) have suggested that the ratios of the time spent responding on the components of a concurrent schedule conform to the same equations as the ratios of the rates of responding.

$$
\frac{T_{k}}{T_{t}}=\frac{P_{k}}{P_{t}}=\frac{k_{k} R_{k}}{k_{t} R_{t}}
$$

Equation 4 would reduce to an equality between the ratios of the time spent responding, or the ratios of the rates of responding, and the ratios of the rates of reinforcement obtained from keypecking and treadle-pressing if the $\mathbf{k}$ parameters had not been systematically different for the two types of responding. This equality has been called the matching law (Herrnstein, 1970).

Baum (1974) proposed a more general form of the matching law. He stated that the ratios of the rates of responding and the ratios of the time spent responding on the components of a concurrent schedule will equal a constant (a) times the ratio of the rates of reinforcement obtained from the components raised to a power (b). Baum's equation was based on studies in which the same type of responses produced reinforcers during the two-component schedules. Therefore, the $\mathrm{k}$ parameters were assumed to be identical for the two components. Equation 5 presents an extension of Baum's equation to the present situation, in which the $\mathrm{k}$ parameters were not identical.

$$
\frac{T_{k}}{T_{t}}=\frac{P_{k}}{P_{t}}=a\left(\frac{k_{k} R_{k}}{k_{t} R_{t}}\right) \text {. }
$$

Equation 5 could be tested by taking the logarithm of both sides of the equation. The results should be a straight line. The slope will equal $b$ and the $y$-intercept will be the logarithm of a. Figure 3 presents logarithms of both sides of Equation 5. That is, Figure 3 represents the logarithm of the ratio of the rates of responding emitted on, and the logarithm of the ratios of the time spent responding on, the components of each concurrent schedule plotted as a function of the logarithm of the ratio predicted for that schedule. The predicted ratio was calculated according to the formula in parentheses on the right side of Equation 5. The time spent responding on each component schedule was recorded by a timer which began with the first response emitted on that component and ended with the first response emitted on the other component. All of the points plotted in Figure 3 are based on the mean of the statistics obtained over the last five sessions for which each schedule was presented. All ratios were calculated by dividing the appropriate statistic for keypecking by the equivalent statistic for treadle-pressing. Missing points indicate that the logarithm of the ratio could not be calculated because the ratio ecualed 0 .

The straight lines which best fit the points plotted on each set of axes in Figure 3 have been estimated by a least squares procedure. These equations appear in Table 3. The equations have been reported for all

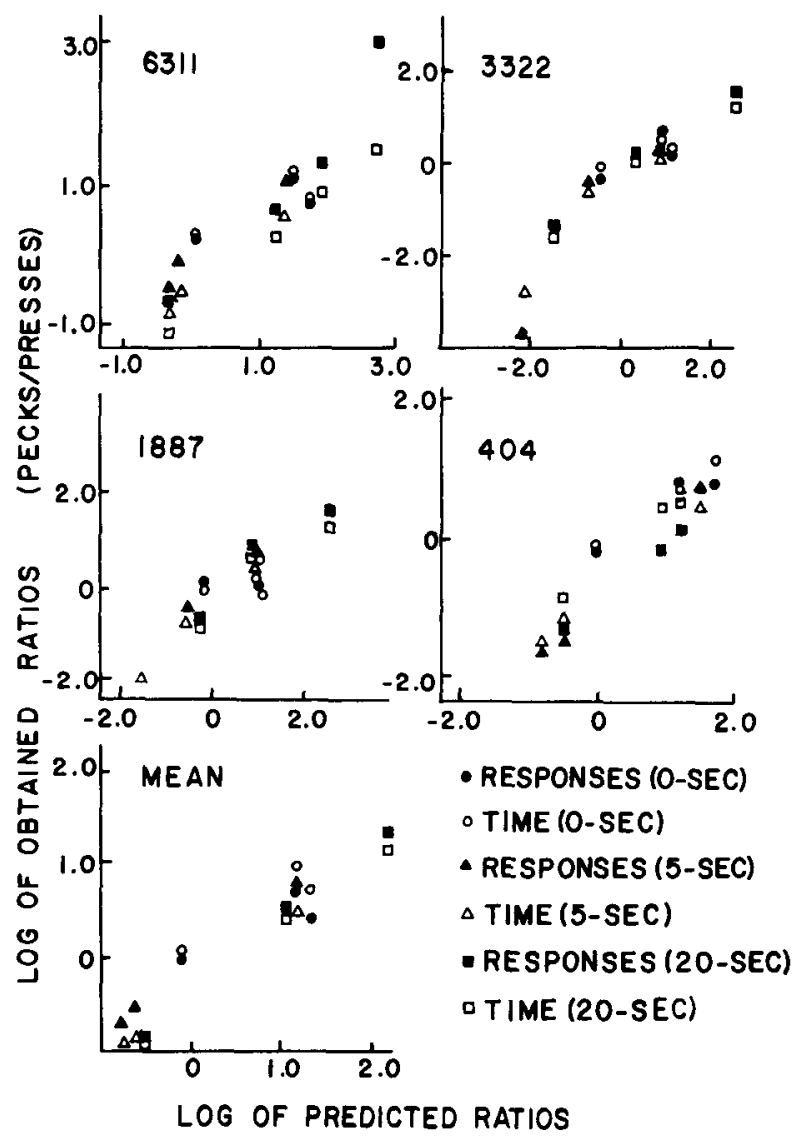

Figure 3. Logarithms of the ratios of the rates of responding emitted (closed points) and the logarithms of the ratios of the time spent responding (open points) on the components of each concurrent schedule plotted as a function of the logarithms of the ratios predicted for that schedule from Equation 1, the subject's simple schedule responding, and the rates of reinforcement obtained from the components. All ratios were calculated by dividing the statistics for keypecking by the statistic for treadlepressing. The fifth set of axes represents the mean of all subjects. The other four sets of axes represent individual subjects. All points are based on the means of the statistics generated over the last five sessions for which each schedule was presented. 
Table 3

Logs of Ratios of Response Rates and Logs of Ratios of Time Spent Responding as a Function of the Logs of the Ratios of the Obtained Rates of Reinforcement Times the Ratios of the $k$ Parameters

\begin{tabular}{|c|c|c|c|c|c|c|c|c|c|c|c|c|c|}
\hline \multirow{3}{*}{$\frac{\text { Subject }}{6311}$} & & & & \multicolumn{10}{|c|}{ Data From Schedules With } \\
\hline & \multicolumn{3}{|c|}{ All Data } & \multicolumn{4}{|c|}{$0-\mathrm{Sec}$ COD } & \multicolumn{3}{|c|}{ 5-Sec COD } & \multicolumn{3}{|c|}{$20-\mathrm{Sec} \mathrm{COD}$} \\
\hline & $y=$ & $.72 x-.23$ & $(.86)$ & $y=$ & $.57 x+$ & 0 & $(.91)$ & $y=.70 x-$ & 0 & $(.77)$ & $y=$ & $.85 x-.54$ & $(.94)$ \\
\hline 3322 & $y=$ & $.85 x-.37$ & $(.84)$ & $y=$ & $.35 x+$ & 0 & $(.64)$ & $y=1.30 x-$ & 0 & $(.90)$ & $y=$ & $.70 x-.31$ & $(.99)$ \\
\hline 1887 & $y=$ & $.78 x-.26$ & $(.86)$ & $y=$ & $.46 \mathrm{x}+$ & 0 & $(.50)$ & $y=.95 x-$ & 0 & $(.88)$ & $y=$ & $.79 x-.34$ & $(.95)$ \\
\hline 404 & $y=$ & $.86 x-.58$ & $(.92)$ & $y=$ & $.55 \mathrm{x}-$ & 0 & $(.97)$ & $y=.82 x-$ & 0 & $(.61)$ & $y=$ & $.80 x-.62$ & $(.86)$ \\
\hline Mean & $y=$ & $.70 x-.24$ & $(.91)$ & $y=$ & $.55 x+$ & 0 & $(.88)$ & $y=.75 x-$ & 0 & $(.85)$ & $y=$ & $.78 x-.45$ & $(.98)$ \\
\hline
\end{tabular}

data, and they have been reported separately for the data generated when the three different values of the COD were programmed. The proportion of the variance in the data which was accounted for by each equation appears in parentheses after it. The equations have not been reported separately for the ratios of the rates of responding emitted during, or for the ratios of the time spent responding on, the component schedules because the equations for these two statistics were not systematically different.

Several conclusions emerge from Table 3. First, Equation 5 described the data well. It accounted for $84 \%$ to $92 \%$ of the variance in the data generated by all of the schedules. Second, the equation accounted for a larger percentage of the variance in the data when the COD was $20 \mathrm{sec}$ long than when it was 0 or $5 \mathrm{sec}$ long for at least three of the four subjects. Third, the slopes of the lines presented in Table 3 were less than 1.0 for all subjects and all COD durations except for Subject 3322 under the 5-sec COD duration. Fourth, the slopes were closer to 1.0 when the COD was 5 or $20 \mathrm{sec}$ long than when it was $0 \mathrm{sec}$ long. But there were no consistent differences between the slopes for the 5- and 20-sec COD durations. Finally, the y-intercepts of the lines equaled 0 for all subjects when the COD was 0 or $5 \mathrm{sec}$ long. The y-intercepts were less than 0 for all subjects when the COD was $20 \mathrm{sec}$ long.

\section{DISCUSSION}

Several conclusions emerge from this study. First, Equation 1 described the subjects' treadle-press responding at least as well as it described their keypeck responding. Equation 1 accounted for $38 \%$ to $96 \%$ of the variance in keypecking for single subjects and for $85 \%$ of the variance for the mean of all subjects. Equation 1 accounted for $76 \%$ to $95 \%$ of the variance in treadle-pressing for single subjects and for $91 \%$ of the variance for the mean of all subjects.

Second, the results conformed to Herrnstein's interpretation of his $\mathbf{k}$ and $\mathbf{R}_{\mathbf{0}}$ parameters (Herrnstein, 1974). The size of the $k$ parameter did vary with the response used to measure it. The size of the $R_{0}$ parameter did not vary with the response. Figure 1 shows that the k parameter was larger for keypecking than it was for treadle-pressing for each subject and for the mean of all subjects. $\mathbf{R}_{0}$ was larger for keypecking than for treadle-pressing for two subjects but smaller for the other two.

Third, the rates of keypecking and treadle-pressing emitted during the concurrent schedules were correlated with, but were not equal to, the rates of responding predicted by Equation 1 and the subject's simple schedule responding. Only 2 of the 15 straight lines, which related the obtained rates of responding to the predicted rates for particular COD durations, accounted for less than $70 \%$ of the variance in the data. But the equations of the lines reported in Table 2 were not $\mathrm{y}=1.0 \mathrm{x}+0$, as they should have been if the obtained rates of responding had exactly equaled the predicted rates. Only 3 of the 15 lines reported in Table 2 for particular COD durations had a slope which fell within \pm .1 of 1.0 , and the devations from 1.0 occurred in a consistent direction. Seventeen of the 20 slopes were less than 1.0.

It is doubtful that further increases in COD duration would have produced a closer fit of the predicted to the obtained response rates in the present experiment. Increasing the COD duration from $0 \mathrm{sec}$ to 5 or $20 \mathrm{sec}$ did improve the fit. The slopes of the lines reported in Table 2 were closer to 1.0 , their $y$-intercepts were closer to 0 , and the lines accounted for a larger percentage of the variance for at least three of the four subjects when the two longer CODs were programmed than when there was no COD. However, increasing the COD duration from 5 to $20 \mathrm{sec}$ did not improve the fit further. The $y$-intercepts became closer to 0 for three of the four subjects, but the slopes became closer to 1.0 for only two subjects and the proportion of the variance in the data which was accounted for improved for only one subject. It is not known whether other procedural factors produced the failure of Herrnstein's equation to describe the response rates perfectly, or whether the equation must be revised.

Fourth, the ratios of the rates of responding, and the ratios of the time spent responding on the components of the concurrent schedule did not fit the predictions of Herrnstein's theory. Herrnstein's prediction is a special case of Equation 5 in which the $a$ and $b$ parameters both equal 1.0. Therefore, $a$ straight line with a slope equal to 1.0 and a y-intercept equal to 0 should describe the data when Equation 5 is plotted on log-log coordinates, as it was in Figure 3. As predicted, the $y$-intercepts of the lines plotted in 
Figure 3 equaled 0 when the $C O D$ was 0 or $5 \mathrm{sec}$ long, but contrary to prediction, the slopes were usually less than 1.0 regardless of the COD duration.

Fifth, Baum's generalization of Herrnstein's equation described the data well. It requires that straight lines describe the data presented in Figure 3, but it does not require that the slopes of these lines equal 1.0 , or that their y-intercepts equal 0 . Straight lines accounted for $84 \%$ to $92 \%$ of the variance in the data in Figure 3 when all data were considered. They described the ratios of the time spent responding as well as the ratios of the rates of responding.

The only deviation from the predictions of Baum's equation was the curvilinear appearance of the results for Subjects 6311 or 3322 at large negative values of the predicted and obtained ratios. However, this curvilinearity did not appear for Subjects 1887 or 404, or for the mean of all subjects. Another study should examine these functions at very low ratios in greater detail.

It is not known whether Baum's generalization of Herrnstein's equation will continue to provide the best description of the results of future experiments or whether Herrnstein's equation may prove satisfactory. Baum (1974) has argued that several procedural problems may produce deviations of the $a$ and $b$ parameters of his equation from the 1.0 values predicted by Herrnstein. Several of these factors may have produced slopes which were less than 1.0 in the present experiment. These factors include poor discrimination between the components, deprivations which are too severe, and COD durations which are too short.

Discrimination between the components may have been poorer in this experiment than in experiments which employ concurrent schedules which require keypecking for reinforcement in both components. The stimulus which signals the component appears directly on the response key when pigeons peck keys. The stimulus appeared on a response key located near, but not on, the treadle in this experiment. An experiment which placed the discriminative stimulus on the treadle might produce slopes closer to Herrnstein's prediction of 1.0 .

The deprivation conditions used in this experiment may have been too severe to produce slopes equal to 1.0. The subjects were maintained at $80 \%$ to $85 \%$ of their free-feeding weights. The present experiment should be repeated using subjects maintained at a higher percentage of their free-feeding weights.

Finally, experiments might be conducted which employed CODs longer than $20 \mathrm{sec}$. Again, the use of a COD which is longer than $20 \mathrm{sec}$ probably would not produce slopes closer to 1.0 . The schedules which employed the 20-sec COD did not produce lines with slopes which were consistently closer to 1.0 than those which employed the 5-sec COD. However, little is known about the role of the COD in regulating concurrent keypeck/treadle-press responding, and it should be investigated.
It also is not known why the y-intercepts of the lines presented in Table 3 deviated from 0 when the COD duration increased from 0 or $5 \mathrm{sec}$ to $20 \mathrm{sec}$. The fact that the intercepts became negative rather than positive is surprising, however. The negative intercepts indicate that choice was biased in favor of treadle-pressing, but keypecking is usually assumed to predominate over other responses in situations involving pigeons, lighted response keys, and food reinforcers (e.g., Brown \& Jenkins, 1968). The bias in favor of pressing does not necessarily, however, indicate a preference for pressing per se. The response key was always located to the subjcct's left and the treadle was located to its right, as it faced the wall containing the food magazine. Perhaps the bias in favor of pressing actually represented a position preference. Alternatively, the bias in favor of pressing may indicate that the subjects actually obtained more food per reinforcer when responding on the treadle than when pecking the key. The position of the treadle may have facilitated movement to the food magazine once it became available. Movement from the key to the food magazine may have required more time. An experiment should vary the location of the key and treadle and it should record the time actually spent eating during each reinforcer.

\section{REFERENCES}

BaUM, W. M. On two types of deviation from the matching law: Bias and under-matching. Journal of the Experimental Analysis of Behavior, 1974, 22, 231-242.

BAUM, W. M. Time-based and count-based measurement of preference. Journal of the Experimental Analysis of Behavior. 1976, 26, 27-35.

Baum, W. M., \& Rachlin, H. C. Choice as time allocation. Journal of the Experimental Analysis of Behavior, 1969, 12 , 861-874.

Brown. P. L.. \& Jenkins, H. M. Auto-shaping of the pigeon's key-peck. Joumal of the Experimental Analysis of Behavior. 1968. 11, 1-8.

Catania, A. C., \& Reynolds, G. S. A quantitative analysis of the responding maintained by interval schedules of reinforcement. Journal of the Experimental Analysis of Behavior, 1968, 11, 327-383.

CoHEN, I. L. A note on Herrnstein's equation. Journal of the Experimental Analysis of Behavior, 1973, 19, 527-528.

DEVILLIERS, $P$. Choice in concurrent schedules and a quantitative formulation of the law of effect. In W. K. Honig \& J. E. R. Staddon (Eds.), Handbook of operant behavior. Englewood Cliffs, N.J: Prentice-Hall, 1977. Pp. 233-287.

HERRNSteIn, R. J. On the law of effect. Journal of the Experimental Analysis of Behavior, 1970, 13, 243-266.

HERRNSTEIN, R. J. Formal properties of the matching law. Journal of the Experimental Analysis of Behavior, 1974, 21, 159-164.

Herrestein, R. J., \& Loveland, D. H. Hunger and contrast in a multiple schedule. Journal of the Experimental Analysis of Behavior, 1974, 21, 511-517.

Lawson, C. L., \& Hanson, R. J. Solving least square problems. Englewood Cliffs, N.J: Prentice-Hall. 1974.

Shuld. R. L., \& Pliskoff. S. S. Changeover delay and concurrent schedules: Some effects on relative performance measures. Journal of the Experimental Analysis of Behavior, 1967, 10, $517-527$

(Received for publication October 28, 1977 revision accepted April 17. 1978.) 